\title{
Targeting the Oligomerization of BCR/ABL by Membrane Permeable Competitive Peptides Inhibits the Proliferation of Philadelphia Chromo- some Positive Leukemic Cells
}

\author{
Afsar Ali Mian ${ }^{1}$, Marion Schüll ${ }^{1}$, Claudia Oancea ${ }^{1}$, Yousef Najajreh ${ }^{2}$, Jamal Mahajna ${ }^{3}$, \\ Amiram Goldblum ${ }^{4}$, Oliver Gerhard Ottmann ${ }^{1}$, Tim Beissert ${ }^{1, *}$ and Martin Ruthardt ${ }^{1, *}$ \\ ${ }^{I}$ Department of Hematology, Goethe University, Frankfurt, Germany \\ ${ }^{2}$ Faculty of Pharmacy, Al-Quds University, Jerusalem-Abu Dies, Palestine \\ ${ }^{3}$ Migal-Galilee Technology Center, Kiryat Shmona, Israel \\ ${ }^{4}$ Department of Medicinal Chemistry and Natural Products, Hebrew University, Jerusalem, Israel
}

\begin{abstract}
The BCR/ABL fusion protein is the hallmark of Philadelphia Chromosome positive ( $\mathrm{Ph}+$ ) leukemia. The constitutive activation of the ABL-kinase in BCR/ABL cells induces the leukemic phenotype. Targeted inhibition of $\mathrm{BCR} / \mathrm{ABL}$ by small molecule inhibitors reverses the transformation potential of $\mathrm{BCR} / \mathrm{ABL}$. Recently, we definitively proved that targeting the tetramerization of $\mathrm{BCR} / \mathrm{ABL}$ mediated by the N-terminal coiled-coil domain $(\mathrm{CC})$ using competitive peptides, representing the helix-2 of the $\mathrm{CC}$, represents a valid therapeutic approach for treating $\mathrm{Ph}+\mathrm{leukemia}$. To further develop competitive peptides for targeting BCR/ABL, we created a membrane permeable helix-2 peptide (MPH-2) by fusing the helix-2 peptide with a peptide transduction tag. In this study, we report that the MPH-2: (i) interacted with $\mathrm{BCR} / \mathrm{ABL}$ in vivo; (ii) efficiently inhibited the autophosphorylation of BCR/ABL; (iii) suppressed the growth and viability of $\mathrm{Ph}+$ leukemic cells; and (iv) was efficiently transduced into mononuclear cells (MNC) in an in vivo mouse model.
\end{abstract}

This study provides the first evidence that an efficient peptide transduction system facilitates the employment of competitive peptides to target the oligomerization interface of BCR/ABL in vivo.

Keywords: Philadelphia Chromosome-positive leukemia, BCR/ABL, molecular targeting, competitive peptide, oligomerization.

\section{INTRODUCTION}

The BCR/ABL fusion protein is the hallmark of Philadelphia chromosome-positive $(\mathrm{Ph}+)$ leukemia. $\mathrm{BCR} / \mathrm{ABL}$ is characterized by deregulated and constitutively activated ABL tyrosine kinase (TK), which determines its transformation potential [1]. Cellular transformation and leukemogenesis are strictly dependent on the TK activity of BCR/ABL [25]. Molecular-targeted therapy with selective ABL-kinase inhibitors (AKI) such as Imatinib, Dasatinib, or Nilotinib induces complete hematological and cytogenetic remission in the majority of $\mathrm{Ph}+$ leukemia patients [6]. However, in advanced stage disease, relapse frequently occurs, and is accompanied by resistance to further treatment with kinase inhibitors. In the majority of the cases, the development of resistance is due to clones harboring point mutations in the $\mathrm{ABL}$ portion of the fusion protein that interfere with the binding of the inhibitors, and these clones are selected with continuous exposure to AKIs [7,8].

*Address correspondence to these authors at the Laboratory for Tumor Stem Cell Biology, Med. Klinik II/Hämatologie, Klinikum der Goethe Universität Frankfurt, Theodor Stern Kai 7, 60590 Frankfurt Germany;

Tel: -49-69-6301-5338; Fax: -49-69-6301-6131;

E-mails: ruthardt@em.uni-frankfurt.de, beissert@em.uni-frankfurt.de
Tetramerization of ABL through the N-terminal coiledcoil region $(\mathrm{CC})$ of $\mathrm{BCR}$ is essential for aberrant $\mathrm{ABL}$ kinase activation $[9,10]$.

The CC contains the helix alpha 1 (a.a. 5-15) and alpha 2 (a.a. 28-67), which are separated by a flexible loop. The dimer interface is formed by the direct interaction of the helices- 2 of each monomer, while the helix-1 from one monomer swings back and packs against the "outside" of the helix-2 dimer, and interacts with the helix-2 of the other monomer [11]. Deletion of the helix-2 impairs oligomerization and reduces kinase activity [12]. Recently, we have shown that targeting the $\mathrm{CC}$-domain forces $\mathrm{BCR} / \mathrm{ABL}$ into a monomeric conformation, which abolishes its transformation potential by interfering with its kinase activity. This also increases the sensitivity of the leukemic cells to Imatinib $[9,13]$.

Peptide-based molecular targeting is emerging as an important therapeutic approach for treating human cancers [14]. The obvious limitations of using peptides as therapeutics are poor permeability and low selectivity. A potential strategy to overcome these limitations is the peptide transduction (PT) system, which involves conjugating the peptide of interest to a protein transduction domain (PTD), conferring the capacity to pass through the cell membrane of living 
cells [15]. All of the different PTDs that have been identified contain stretches of 9-11 a.a., which are usually basic and predominantly consist of arginine residues [16]. The efficiency of the receptor-independent uptake mediated by the different PTDs varies with the conjugated peptides and target cells [17]. An example of a PTD is HIV-TAT, which is derived from the human immunodeficiency viral protein TAT, and contains an arginine-rich sequence of 11 a.a. [18, 19]. Rapid receptor-independent uptake of TAT-conjugated peptides occurs in many cell types and animals $[17,20,21]$.

The aim of this study was to develop a novel cell based in vivo delivery system. The results generated from this study may significantly contribute to the advancement of the field of cell and peptide based therapeutics to treat Imatinibresistant $\mathrm{Ph}+$ leukemia.

\section{MATERIAL AND METHODOLOGY}

\section{Plasmids}

All expression vectors used in this study were based on pPRIBA2, which provides an in-frame Strep Tag as well as a His-tag (IBA - BioTAGnology, Göttingen, Germany). pPRIBA2 was converted into a Gateway ${ }^{\circledR}$-destination vector by the introduction of a Gateway ${ }^{\circledR}$ cassette, according to the manufacturer's instructions (Invitrogen, Karlsruhe, Germany). All related inserts were available in the Gateway ${ }^{\circledR}$ entry-vector (pENTR1A), and were shuttled into the destination vectors using the "LR-clonase" enzyme kit (Invitrogen). The pENTR1A with GFP and the helix-2-GFP fusion peptide ( $\mathrm{pE}-\mathrm{GFP}$ and $\mathrm{pE}-\mathrm{H} 2-\mathrm{GFP}$, respectively) have been previously described [13]. For the generation of the HIVTAT-H2GFP fusion peptides (here referred to as MPH-2), the following linkers were used $5^{6}$ - gcgectacggecgcaagaagcgacgtcagagacgacgcgtcaac- $3^{6}$ and $5^{6}$ - tatcgttgacgegtcgtctctgacgtcgcttcttgcggccgtag- $3^{\circ}$. Retro-HIV-TAT-H2GFP fusion peptides were generated using the linkers $5^{6}$ - gcgeccgaagacgccaacgaaggaagaaacgggtcaac- $3^{6}$ and $5^{6}$-tatcgttgacccgtttcttccttcgttggcgtcttcgg $-3^{\circ}$. The resulting PCR products were all confirmed by sequencing, and were cloned into the pPRIBA2 vector using a BsaI site, and recombined with $\mathrm{pE}$ GFP and pE-H2GFP. The pPRIBA2-GFP and pPRIBA2-H2GFP vectors were constructed by directly shuttling $p E-G F P$ and pE-H2GFP into the pRIBA2 vector.

\section{CELL LINES}

Nalm-6, BV-173, K562 and Tom-1 cells were obtained from the German Collection of Microorganisms and Cell Cultures (DSMZ, Braunschweig, Germany). Nalm-6, BV173, K562 were maintained in RPMI 1640 medium supplemented with $10 \%$ fetal calf serum (FCS), and Tom-1 was maintained in 20\% FCS (Invitrogen, Karlsruhe, Germany). Rat-1 and 293 cells were cultured in DMEM supplemented with $10 \%$ FCS. Cell growth was assessed by Trypan-blue dye exclusion. Proliferation was assessed with the XTT proliferation kit (Roche, Mannheim, Germany) according to the manufacturer's instructions.

\section{PRODUCTION OF RECOMBINANT TAT- FUSION PROTEINS}

The strep-tagged H2-GFP, TAT-GFP and MPH-2 peptides were produced in E.coli BL21 from pPRIBA2 vectors upon induction with $0.5 \mathrm{mM}$ isopropyl thiogalactoside
(IPTG) overnight at $25^{\circ} \mathrm{C}$. Bacterial lysates were prepared in buffer W (100 mM Tris- $\mathrm{HCl} \mathrm{pH} 8.0,150 \mathrm{mM} \mathrm{NaCl}, 1 \mathrm{mM}$ EDTA, $0.1 \%$ Tween) containing a complete protease inhibitor cocktail (Roche Basel Switzerland), sonicated, and cleared by centrifugation (10.000 g for $10 \mathrm{~min}$.). Further purification of the STREP-tagged peptides was performed using a STREPtactin Matrix (IBA - BioTAGnology). The beads were washed 4 times with buffer $\mathrm{W}$, and the proteins were eluted with elution buffer at room temperature for 15 min. The buffer was exchanged with PBS using PD-10 columns (Amersham/Pharmacia Biotec, Freiburg, Germany), and the endotoxin was removed using endotoxin free columns (Profos AG, Regensburg, Germany). The amount of protein was quantified by comparing the samples to a bovine serum albumin (BSA) standard curve. Samples were stored at $-20^{\circ} \mathrm{C}$ in $15-20 \%$ glycerol for further use. Quantification of proteins was performed using SDS-PAGE followed by coomassie-staining.

\section{DETERMINATION OF TAT-FUSION PROTEIN UPTAKE}

To determine the uptake efficiency of the fusion proteins, $1 \times 10^{5}$ cells/well of 293 T, Rat- 1 , Nalm-6, BV-173, K562 and Tom-1 were plated in a 12-well plate for 12-16 hr. Cells were then incubated with H2-GFP, TAT-GFP or MPH-2 (1 $\mu \mathrm{M}$ each) for $3 \mathrm{hr}$. The cells were washed with PBS, harvested, and the uptake efficiency was measured by quantification of the GFP-positivity by fluorescent activated cell sorting (FACS).

\section{WESTERN BLOT}

Western blot analyses were performed according to widely established protocols. Lysates were obtained using E1A buffer - $150 \mathrm{mM} \mathrm{NaCl}, 50 \mathrm{mM}$ Tris- $\mathrm{HCl} \mathrm{pH} 8.0,50$ $\mathrm{mM}$ HEPES, $0.1 \%$ NP40 and protease-inhibitors (Roche Basel, Switzerland) to separate the soluble cytoplasmic fraction from the membrane-associated (NP-40 insoluble fraction). The following antibodies were used: anti-ABL $(\alpha-A B L)$ (St. Cruz Biotechnology, Santa Cruz, CA, USA), anti-phosphorylated ABL specific for the phosphorylated tyrosine-residue 245 ( $\alpha$-p-ABL-Tyr-245) (Upstate-Biotechnology, Lake Placid, NY, USA), anti-GFP (Santa Cruz Biotechnology, Santa Cruz, CA, USA). Blocking and antibody incubation steps were performed in 5\% low fat dry milk, followed by washing in Tris-buffered saline (TBS; 10 $\mathrm{mM}$ Tris- $\mathrm{HCl} \mathrm{pH} 8.0,150 \mathrm{mM} \mathrm{NaCl}$ ) containing $0.1 \%$ Tween20 (TBST).

\section{PULL-DOWN ASSAYS}

BV173 cells were exposed to $1 \mu \mathrm{M}$ H2-GFP, TAT-GFP and $\mathrm{MPH}-2$. After $3 \mathrm{hr}$, the cells were washed, trypsinized and lysed in E1a buffer. The cell lysates were clarified by centrifugation $(10 \mathrm{~min}$ at $10.000 \mathrm{~g})$. An aliquot of total protein $(1 \mu \mathrm{g})$ was incubated with $10 \mu \mathrm{L}$ STREPtactin Matrix (IBA) overnight at $4^{\circ} \mathrm{C}$. The mixture of sepharose and protein was washed 4 times with E1A buffer $(150 \mathrm{mM}, \mathrm{NaCl}$, $5 \mathrm{mM}$, HEPES $50 \mathrm{mM}$ pH 7.0, EDTA $5 \mathrm{mM}$ pH 8.0, 1\% Triton, $\mathrm{NaVO}_{4} 2 \mathrm{mM}$ and $1 \mathrm{X}$ protease inhibitor cocktail Roche, Mannheim, Germany). The bound protein was eluted with elution buffer (IBA), resolved by SDS-PAGE, and visualized by staining the blots with an $\alpha$-ABL antibody. 


\section{ANIMAL EXPERIMENTS}

C57 BL/6N female mice (Harlan Winkelmann, Borchen, Germany) 6 to 8 weeks old were kept on sterile bedding in filter-top cages. They were provided with sterile food and water ad libitum. Peptides dissolved in PBS at a dosage of $2.5 \mathrm{mg} / \mathrm{kg}$ were inoculated i.v. into recipient mice. Negative control mice received the same volume of phosphatebuffered saline (PBS). Animals were sacrificed by $\mathrm{CO}_{2}-$ asphyxiation after $15 \mathrm{~min}, 2 \mathrm{hr}, 6 \mathrm{hr}$, and $24 \mathrm{hr}$ of treatment. Peripheral blood (PB) was obtained from the heart, and bone marrow (BM) was harvested from the femur and tibiae by flushing the bones with a syringe and 26-gauge needle. Spleen cells were isolated by passing the tissue through a 40 $\mu \mathrm{M}$ Nylon cell strainer (Beckton-Dickinson, Le Pont de Claix, France). For analysis of GFP expression, the MNCs were enriched using a Ficoll density gradient, and GFP expression was measured by fluorescence activated cells sorting (FACS).

\section{RESULTS}

\section{HIV-TAT-Fusion Peptides were Efficiently Delivered to Fibroblasts}

To determine the most efficient peptide transduction system, we compared the HIV-TAT with the Retro-HIV-TATsequences fused to helix-2. We created fusion peptides containing a Strep-tag (for efficient immunoprecipitation), HIVTAT or Retro-HIV-TAT as the peptide transduction tag, the helix-2 sequence, and GFP as reporter (Fig. 1A). A construct lacking the helix-2 sequence (TAT-GFP) was used as the control in experiments. These fusion peptides were expressed in the E.coli strain BL21, and purified by high affinity chromatography (Fig. 1B). Peptide transduction was performed in the presence/absence of chloroquine, which facilitates the up-take of membrane permeable peptides. Here, we show a higher efficiency of peptide transduction of helix-2 upon fusion with the HIV-TAT (MPH-2), as compared to Retro-HIV-TAT in untransformed Rat-1 fibroblasts (Fig. 1C). Due to its high efficiency, HIV-TAT was used as transduction tag for the remaining studies.

\section{HIV-TAT MEDIATES THE EFFICIENT CELLULAR UPTAKE OF HELIX-2 FUSION PROTEINS}

To confirm that the HIV-TAT fused membrane permeable helix-2 (now referred to as MPH-2) is able to enter leukemic cells, we exposed $\mathrm{Ph}+$ (Tom-1, BV173 and K562) and $\mathrm{Ph}-(\mathrm{Nalm}-6)$ leukemic cells to the HIV-TAT-fusion peptides. Peptides without the TAT-domain (H2-GFP), or TATGFP were used as controls. The uptake rate was assessed by determining the percentage of GFP-positive cells by FACS. As reported in Fig. (2A), both the $\mathrm{Ph}+$ and $\mathrm{Ph}$ - leukemic cell populations were nearly $100 \%$ positive for GFP in the presence of the transduction tag, whereas the cells incubated with control peptides were completely negative. Interestingly, the uptake of MPH-2 was more efficient than the TAT-GFP peptide. To exclude that the GFP-positivity was due to peptides binding to the outer side of the cell membrane without penetrating the cell, we exposed Nalm-6 and BV-173 to H2-GFP, TAT-GFP or MPH-2, and performed immunoblots on cell lysates that excluded the membrane fraction. Both of the cell lines expressed the peptides corresponding to the HIV-TAT tag, which clearly confirmed greater uptake of MPH-2 compared to the TAT-GFP control (Fig. 2B).

\section{A}

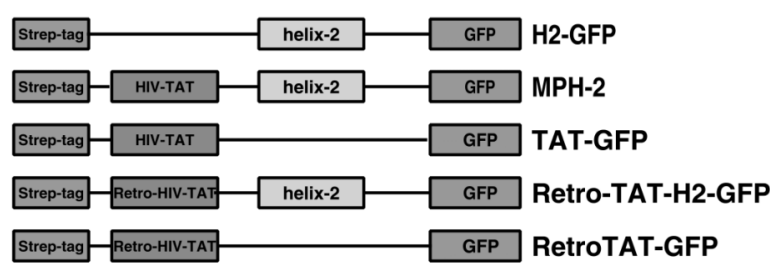

B
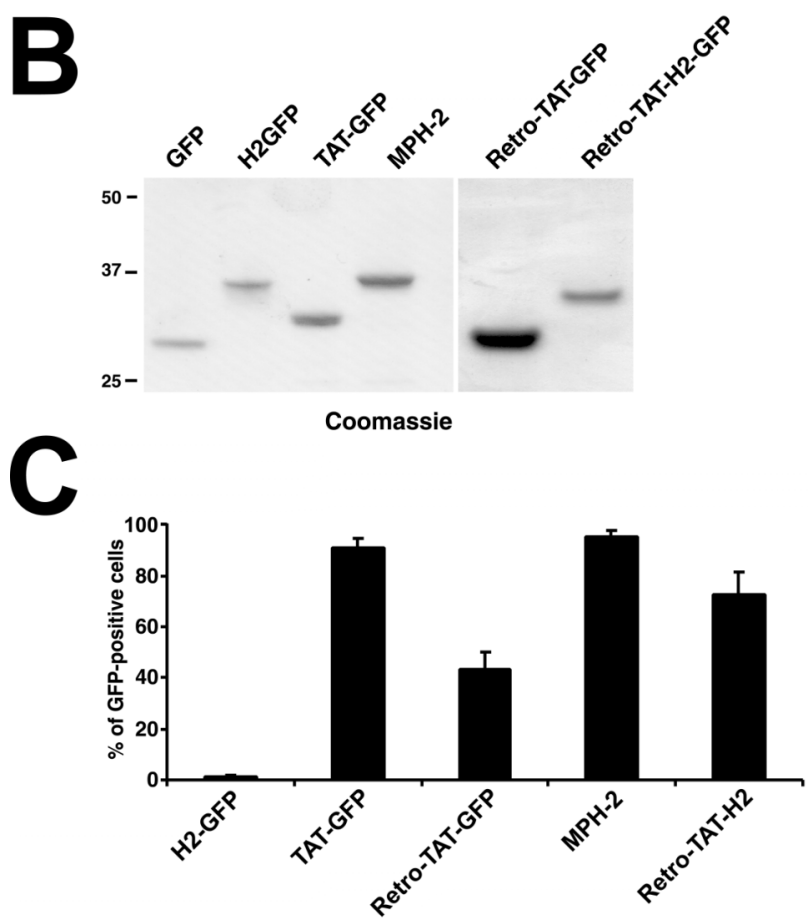

Fig. (1). Recombinant membrane permeable peptides. A Schematic representation of the fusion peptides used in this study with the indicated tags. B Recombinant peptides on a coomassie-stained SDS-PAGE Gel. C Peptide transduction efficiency with the indicated peptide transduction tag fused to helix-2 in Rat-1 fibroblasts, provided as percentage of GFP-positive cells. The data represent the mean of 3 independent experiments with SD.

To determine the stability of MPH-2, Rat-1 fibroblasts were exposed to TAT-GFP, MPH-2 and H2-GFP for $3 \mathrm{hr}$. Then the cells were extensively washed, trypsinized, and seeded in fresh media. GFP expression was measured after 30, 60 and $120 \mathrm{~min}, 6 \mathrm{hr}$ and $24 \mathrm{hr}$. As depicted in Fig. (2C), GFP was detectable for at least $6 \mathrm{hr}$, showing that the TATfusion peptides were stable for at least $6 \mathrm{hr}$.

Taken together, these data provide evidence that MPH-2 transduces several different cell types with high efficiency, and remains stable for several hours.

\section{MPH-2 INTERACTS WITH BCR/ABL}

To be therapeutically effective, MPH-2 has to inhibit the oligomerization of $\mathrm{BCR} / \mathrm{ABL}$ by competing for the binding to the $\mathrm{N}$-terminal $\mathrm{CC}$-domain of $\mathrm{BCR} / \mathrm{ABL}$. We investigated 

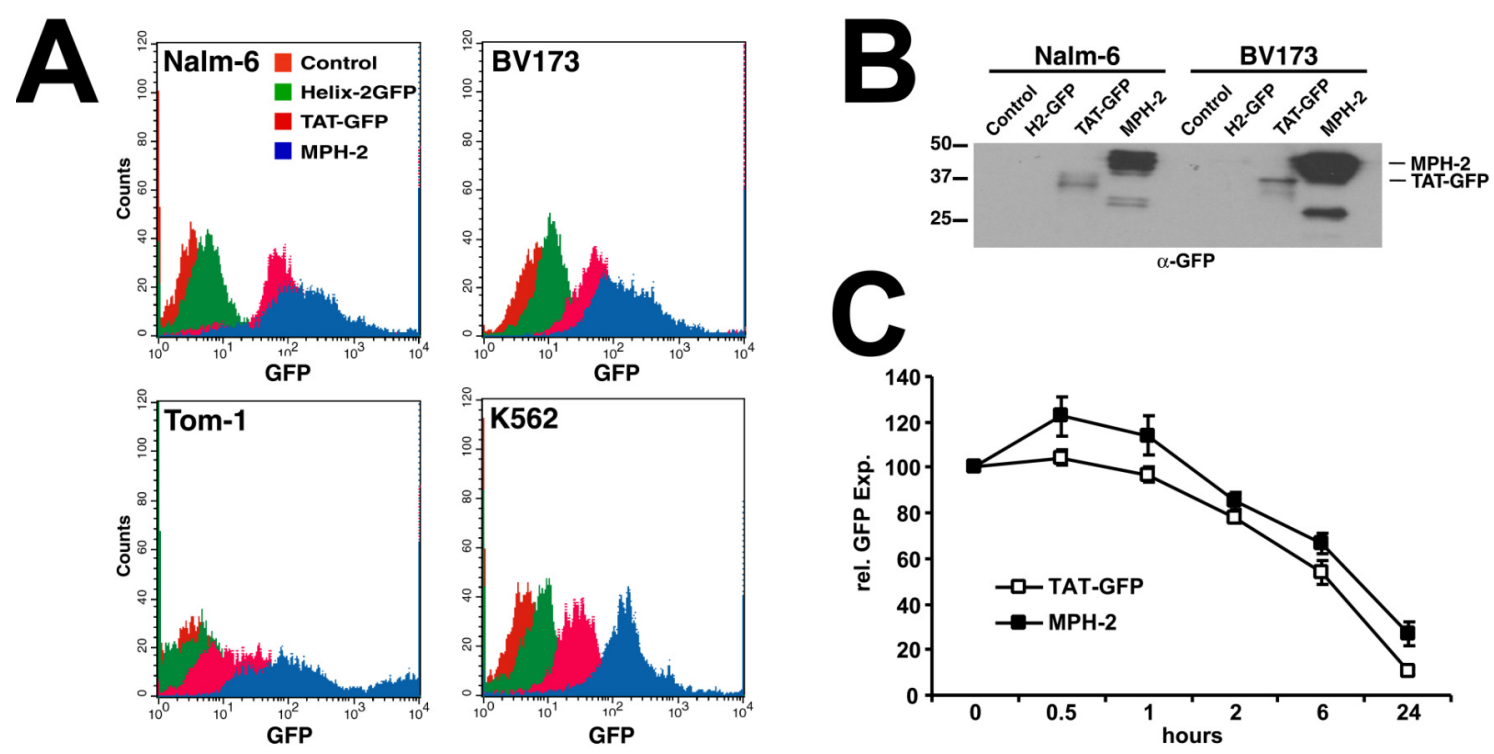

Fig. (2). Uptake of HIV-TAT fusion peptides by leukemic cell lines and primary stem cells. A Ph+ cell lines; Tom-1 (Ph+ ALL), BV173 (CML lymphatic blast crisis) and K562 (CML - myeloid blast crisis), and the Ph- Nalm-6 cells (ALL) were exposed to $1 \mu \mathrm{M}$ of the indicated peptides. GFP expression was determined using FACS. A one representative of 3 independent experiments is provided, as all yielded nearly identical results. B Intracellular uptake of MPH-2. Western blot analysis of the cell lysates cleared from the membrane fraction, and probed with an $\alpha$-GFP-antibody. C Stability of MPH-2. Rat-1 cells were exposed to $1 \mu \mathrm{M}$ of the indicated peptides. GFP expression was determined using FACS at indicated time points.

whether MPH-2 could bind BCR/ABL. We exposed $\mathrm{Ph}+$ BV173 cells to MPH-2, and to H2-GFP and TAT-GFP, which were negative controls. As shown in Fig. (1A), all of the recombinant peptides used in the experiments had a Strep-tag. Lysates were incubated with strep-tactin sepharose to pull down the strep-tagged peptides. Strep-tactin sepharose-bound protein complexes were separated by SDSPAGE, and blotted on a methyl cellulose membrane, which was probed with an $\alpha$-ABL antibody. Here, we show that $\mathrm{MPH}-2$ was able to precipitate $\mathrm{BCR} / \mathrm{ABL}$ from the cell lysates, which confirms that MPH-2 and BCR/ABL directly interact Fig. (3).

\section{MPH-2 EFFICIENTLY REDUCES THE AUTOPHOS- PHORYLATION OF BCR/ABL}

The capacity of MPH-2 to interact with BCR/ABL in vivo prompted us to study its inhibitory effects on the aberrant $\mathrm{BCR} / \mathrm{ABL}$ kinase-expressing cells. We investigated the autophosphorylation status of $\mathrm{BCR} / \mathrm{ABL}$ at the phosphotyrosine residue Y245, which is critical for ABL-kinase activation in the $\mathrm{Ph}+$ cell lines, Tom-1 (Ph+ ALL) and BV173 (lymphatic CML blast crisis), upon exposure to MPH-2. Tom-1 and BV-173 cells were transduced with MPH-2 and TAT-GFP as negative controls. After $3 \mathrm{hr}$, cells were lysed, and a western blot was performed with antibodies directed against the c-ABL and phosphorylated ABL (Y245). As depicted in Fig. (4), in contrast to TAT-GFP, MPH-2 inhibited the autophosphorylation of $\mathrm{BCR} / \mathrm{ABL}$, showing that MPH-2 targets BCR/ABL in patient derived $\mathrm{Ph}+$ leukemic cell lines.

\section{MPH-2 SELECTIVELY INHIBITS PH+ LEUKEMIC CELL LINES}

To definitively establish the inhibitory effects of MPH-2 on the transformation potential of $\mathrm{BCR} / \mathrm{ABL}$, we assessed the growth of human $\mathrm{Ph}+$ patient derived cells. We exposed Tom-1, BV-173, and K562 (myeloid CML blast crisis), and the BCR/ABL negative Nalm- 6 cells to $1 \mu \mathrm{M}$ of MPH-2, and the negative controls, TAT-GFP and helix-2-GFP. Cell viability was monitored by Trypan blue dye exclusion. As shown in Fig. (5A), the growth of Tom-1, BV-173 and K562 were inhibited by MPH-2 in comparison to the controls, but MPH-2 did not exert any influence on the growth of Nalm-6 cells. The inhibitory effects of MPH-2 on the growth of $\mathrm{Ph}+$ leukemic cell lines were confirmed by XTT-proliferation assays. The human $\mathrm{Ph}+$ cell lines Tom-1, BV-173, K562, and the Ph- cell line Nalm- 6 were transduced with $1 \mu \mathrm{M}$ of $\mathrm{MPH}-2$, and the proliferation rate was measured after $48 \mathrm{hr}$ of exposure. As depicted in Fig. (5B), the proliferation of Tom-1 and BV-173 BCR/ABL expressing cells was significantly inhibited by MPH-2, whereas the proliferation of

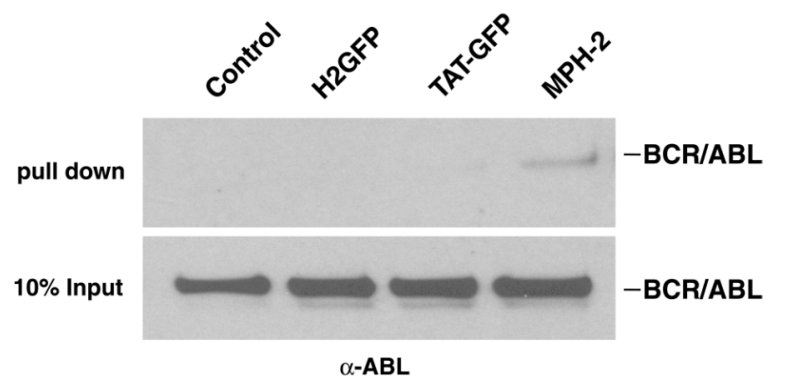

Fig. (3). Interaction between MPH-2 and BCR/ABL. Pull-down of BCR/ABL from BV173 cells exposed to TAT fusion proteins. BV173 were exposed for $3 \mathrm{hr}$ to $1 \mu \mathrm{M}$ of MPH-2 or the indicated control peptides. All fusion peptides harbored the Strep-tag (Figure 1A) and were pulled down by the STREPtactin Matrix. They were analyzed for the presence of bound $\mathrm{BCR} / \mathrm{ABL}$ by probing with the $\alpha$-ABL antibody. As a control, $10 \%$ of the inputs are shown. 

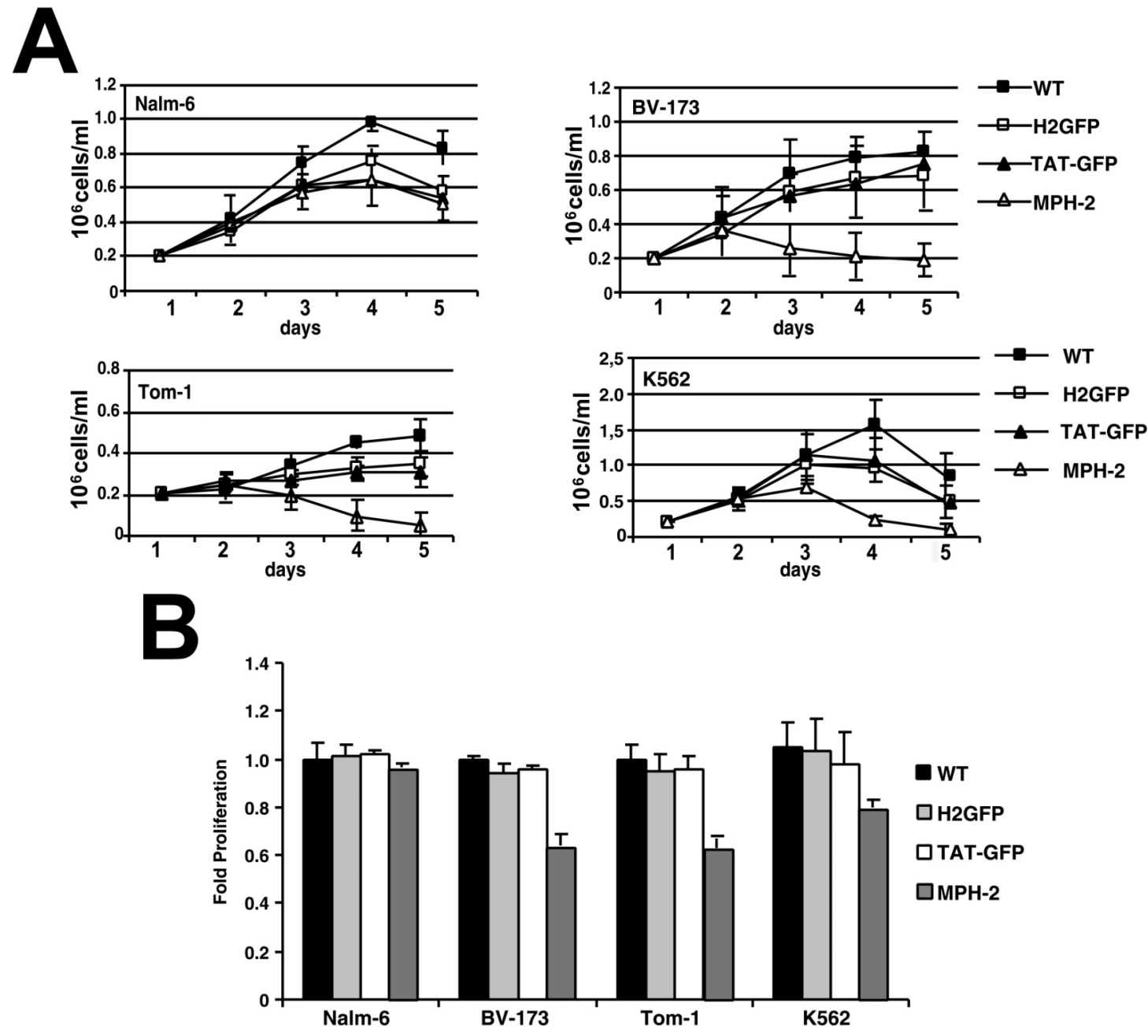

Fig. (4). MPH-2 inhibits the autophosphorylation of BCR/ABL. TOM-1 and BV173 cells were exposed for $3 \mathrm{hr}$ to $1 \mu \mathrm{M}$ of MPH-2. Autophosphorylation was assessed by Western blotting with the $\alpha$-ABL and $\alpha$-p-ABL antibodies directed against whole and phophsorylated ABL, repsectively.

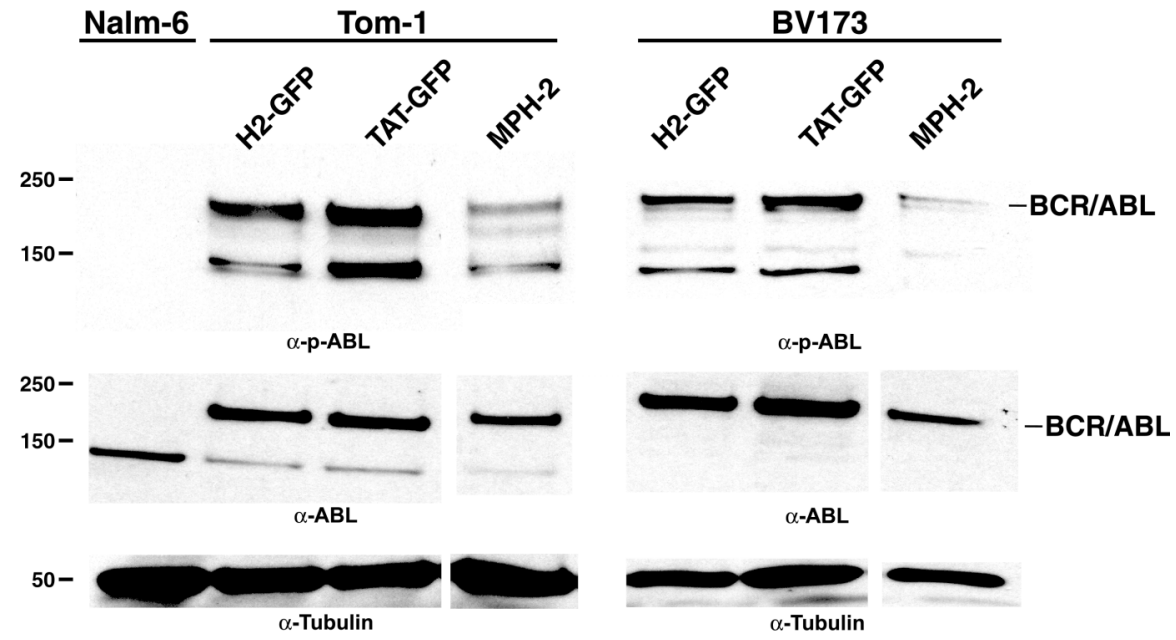

Fig. (5). Growth inhibition of Ph+ leukemic cell lines upon exposure to MPH-2. Ph+ cell lines; Tom-1 (Ph+ ALL), BV173 (CML lymphatic blast crisis) and K562 (CML - myeloid blast crisis), and the Ph- Nalm-6 cells (ALL) were exposed to $1 \mu \mathrm{M}$ of the indicated peptides. A Proliferation was assessed by either the Trypan blue dye exclusion (A) or XTT (B) assay.

K562 was only slightly reduced. No non-specific activity of MPH-2 on Nalm-6 cells was observed.
Taken together, these data indicate that MPH-2 specifically inhibits $\mathrm{Ph}+$ human cell lines. 


\section{TAT-FUSION PROTEIN ARE EFFICIENTLY DELIVERED IN VIVO}

To investigate whether the MPH-2 is efficiently transduced into primary cells we exposed primary Scal ${ }^{+} / \mathrm{lin}^{-}$murine hematopoietic stem cells (HSCs) to MPH-2 for $3 \mathrm{hr}$. We found that these cells were transduced to a similar extent than the above described leukemic cell lines (Fig. 6A). To determine to what extent the TAT fusion peptides are actively transduced in vivo and to assess their in vivo stability, we inoculated i.v. $250 \mu \mathrm{g}$ of TAT-GFP and MPH-2 peptides into recipient mice. MNCs from the peripheral blood and bone marrow and spleen cells were isolated after $15 \mathrm{~min}, 2$ $\mathrm{hr}, 6 \mathrm{hr}$ and $24 \mathrm{hr}$ of treatment. GFP expression was measured using FACS. As shown in Fig. (6B), the GFP expression level peaked at $15 \mathrm{~min}$, was maintained until $6 \mathrm{hr}$, and was completely abolished after $24 \mathrm{hr}$ in the peripheral blood and bone marrow cells. Consistent with peripheral blood, the GFP expression was maximal after $15 \mathrm{~min}$ and maintained until $24 \mathrm{hr}$ in the bone marrow cells (Fig. 6B). In contrast, the spleen cells exhibited maximal GFP expression after $6 \mathrm{hr}$ of treatment, which was completely lost after $24 \mathrm{hr}$ (Fig. 6B). Control mice had no detectable GFP expression in any organ.

In summary, these results demonstrate that TAT-fusion proteins are efficiently delivered to the hematopoietic organs and are pharmacologically stable for a pharmacologically reasonable period of time.

\section{DISCUSSION}

The tetramerization and the formation of high molecular weight complexes are crucial for the leukemogenic potential of $\mathrm{BCR} / \mathrm{ABL}$, and inhibition of this process increases the sensitivity to the kinase inhibitor Imatinib [9]. The aim of the present study was to further develop the disruption of tetramerization as a therapeutic approach, by creating membrane permeable inhibitory peptides and exploring their effectiveness in treating $\mathrm{Ph}+$ leukemia.

We previously showed that the 39 a.a. sequence of the Nterminal BCR coiled-coil region, representing the helix-2, binds to $\mathrm{BCR} / \mathrm{ABL}$ when expressed using a retroviral transduction system [13]. Here, we show that MPH-2, represent- ing the helix-2, fused to a peptide transduction tag effectively binds to $\mathrm{BCR} / \mathrm{ABL}$, which inhibits the aberrant kinase activity of $\mathrm{BCR} / \mathrm{ABL}$, and suppresses the growth of $\mathrm{BCR} /$ $\mathrm{ABL}$ dependent leukemic cell lines.

In this study, we found that the MPH-2 administrated by i.v. injection efficiently transduced the MNCs in the peripheral blood, bone marrow and spleen, and was stabile for about $6 \mathrm{hr}$, which correlated with its in vitro stability.

The potential of the HIV-TAT as a peptide transduction tag was previously extensively explored using the model of TAT fused to $\beta$-galactosidase. These studies showed that TAT fused $\beta$-galactosidase is effectively delivered to many tissues, including the liver, kidney, heart, muscle, lung, spleen, and brain of mice by i.p. injection, and it fully maintains its biological activity [18,22].

A complex formed by TAT and technetium 99 minutes after administering it by i.v. bolus in mice showed a rapid distribution throughout the body, with a gamma imaging pattern consistent with organ perfusion. The complex reached peak organ levels within 5 min after injection (liver $>$ kidney $>$ small intestine $>$ lung $>$ spleen $>$ brain), and displayed modestly rapid blood clearance. Over the subsequent $2 \mathrm{hr}$, the complex was cleared by both renal and hepatobiliary excretion, with activity appearing in the urinary bladder and bowel [23].

These findings along with our data strongly suggest that the TAT-delivered helix-2 peptide may provide the basis for a novel therapeutic approach to treat $\mathrm{Ph}+$ leukemia.

\section{CONFLICTS OF INTERESTS}

The authors do not have any conflict of interests to declare.

\section{ACKNOWLEDGMENTS}

This project was supported by a grant from the Deutsche Forschungsgemeinschaft to M.R., Y.N., J.M., and A.G. (DFG-RU 728/3-2). M.R. is further funded by grants from Deutsche Krebshilfe e.V. (DKH-107063 and DKH-107741), Deutsche José Carreras Leukämie-Stiftung e.V. (DJCLS - R 07/27f), and the Alfred und Angelika Gutermuth Foundation.

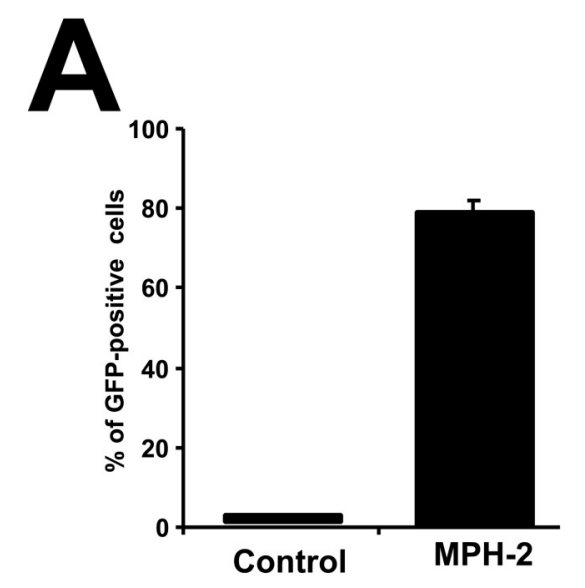

B

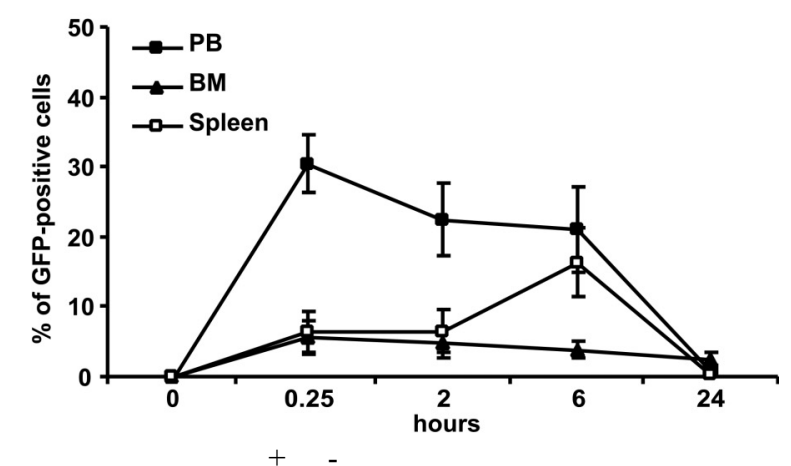

Fig. (6). In vivo transduction of MPH-2. A Transduction efficiency in primary Scal ${ }^{+} /$lin $^{-}$murine hematopoietic stem cells. B Transduction efficiency in vivo. $25 \mu \mathrm{g} / \mathrm{kg}$ of body weight of MPH-2 were injected i.v., and after the indicated time points, 3 mice/group were sacrificed. GFP expression was determined in the MNCs from PB, spleen and BM. 


\section{REFERENCES}

[1] Faderl S, Talpaz M, Estrov Z, O'Brien S, Kurzrock R, Kantarjian, HM. The biology of chronic myeloid leukemia. N Engl J Med 1999; 341: 164-72.

[2] Lugo TG, Pendergast AM, Muller AJ, Witte ON. Tyrosine kinase activity and transformation potency of bcr-abl oncogene products. Science 1990; 247: 1079-82.

[3] Deininger MW, Goldman JM, Lydon N, Melo JV. The tyrosine kinase inhibitor CGP57148B selectively inhibits the growth of BCR-ABL-positive cells. Blood 1997; 90: 3691-98.

[4] Druker BJ, Tamura S, Buchdunger E, et al. Effects of a selective inhibitor of the Abl tyrosine kinase on the growth of Bcr-Abl positive cells. Nat Med 1996; 2: 561-66.

[5] Weisberg E, Griffin JD. Mechanism of resistance to the ABL tyrosine kinase inhibitor STI571 in BCR/ABL-transformed hematopoietic cell lines. Blood 2000; 95: 3498-505.

[6] O'Dwyer ME, Mauro MJ, Druker BJ. STI571 as a targeted therapy for CML. Cancer Invest 2003; 21: 429-38.

[7] Cowan-Jacob SW, Guez V, Fendrich G, et al. Imatinib (STI571) resistance in chronic myelogenous leukemia: molecular basis of the underlying mechanisms and potential strategies for treatment. Mini Rev Med Chem 2004; 4: 285-99.

[8] Deininger M. Resistance to imatinib: mechanisms and management. J Natl Compr Canc Netw 2005; 3: 757-68.

[9] Beissert T, Puccetti E, Bianchini A, et al. Targeting of the Nterminal coiled coil oligomerization interface of BCR interferes with the transformation potential of BCR-ABL and increases sensitivity to STI571. Blood 2003; 102: 2985-93.

[10] McWhirter JR, Galasso DL, Wang JY. A coiled-coil oligomerization domain of Bcr is essential for the transforming function of Bcr-Abl oncoproteins. Mol Cell Biol 1993; 13: 7587-95.

[11] Zhao X, Ghaffari S, Lodish H, Malashkevich VN, Kim PS. Structure of the Bcr-Abl oncoprotein oligomerization domain. Nat Struct Biol 2002; 9: 117-120.

[12] Smith KM, Yacobi R, Van Etten RA. Autoinhibition of Bcr-Abl through its SH3 domain. Mol Cell 2003; 12: 27-37.
[13] Beissert T, Hundertmark A, Kaburova V, et al. Targeting of the Nterminal coiled coil oligomerization interface by a helix-2 peptide inhibits unmutated and imatinib-resistant BCR/ABL. Int J Cancer 2008; 122: 2744-52.

[14] Selivanova G, Iotsova V, Okan I, et al. Restoration of the growth suppression function of mutant $\mathrm{p} 53$ by a synthetic peptide derived from the p53 C-terminal domain. Nat Med 1997; 3: 632-38.

[15] Fawell S, Seery J, Daikh Y, et al. Tat-mediated delivery of heterologous proteins into cells. Proc Natl Acad Sci USA 1994; 91: 664-68.

[16] Zhao M, Weissleder R. Intracellular cargo delivery using tat peptide and derivatives. Med Res Rev 2004; 24: 1-12.

[17] Cao G, Pei W, Ge H, et al. In Vivo Delivery of a Bcl-xL Fusion Protein Containing the TAT Protein Transduction Domain Protects against Ischemic Brain Injury and Neuronal Apoptosis. J Neurosci 2002; 22: 5423-31

[18] Schwarze SR, Ho A, Vocero-Akbani A, Dowdy SF. In vivo protein transduction: delivery of a biologically active protein into the mouse. Science 1999; 285: 1569-72.

[19] Asoh S, Ohsawa I, Mori T, et al. Protection against ischemic brain injury by protein therapeutics. Proc Natl Acad Sci USA 2002; 99: 17107-12.

[20] Denicourt C, Dowdy SF. Protein transduction technology offers novel therapeutic approach for brain ischemia. Trends Pharmacol Sci 2003; 24: 216-18.

[21] Sugioka R, Shimizu S, Funatsu T, et al. BH4-domain peptide from Bcl-xL exerts anti-apoptotic activity in vivo. Oncogene 2003; 22 : 8432-40.

[22] Cai SR, Xu G, Becker-Hapak M, Ma M, Dowdy SF, McLeod HL. The kinetics and tissue distribution of protein transduction in mice. Eur J Pharm Sci 2006; 27: 311-19.

[23] Polyakov V, Sharma V, Dahlheimer JL, Pica CM, Luker GD, Piwnica-Worms D. Novel Tat-peptide chelates for direct transduction of technetium-99m and rhenium into human cells for imaging and radiotherapy. Bioconjug Chem 2000; 11: 762-71.

This is an open access article licensed under the terms of the Creative Commons Attribution Non-Commercial License (http://creativecommons.org/licenses/ by-nc/3.0/) which permits unrestricted, non-commercial use, distribution and reproduction in any medium, provided the work is properly cited. 